\section{Carsten Niebuhr som forlægger}

\section{Af bibliotekar Sven Stouby Pedersen}

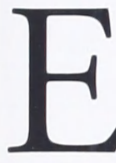
fter hjemkomsten fra den Arabiske Rejse (1761-67) blev Carsten Niebuhr udnævnt til ingeniørkaptajn med rang af kaptajn i garden, men fritaget for tjeneste indtil rejsebeskrivelsen var færdig.

Han var sin egen forlægger, dog betalte kongen omkostningerne ved kobberstikkene.

Endvidere var Niebuhr "til de paa dette Verk forefaldende betydelige Omkostninger allernaadigst bevilget 500 Rd. til enhver af de 3 Deeles udgivelse, hvoraf Beskrivelsen af Arabien og hans Reise Beskrivelse skal bestaae - - - . Iligemaade ere ham de til dette Verk hørende Kobber Plader allernaadigst skienkede og hannem tilladt at giøre sig samme og det hele Verk saa nyttig som han best kan imod at han af hver Tome indleverer til Hans Mayestets particuliere Bibliotheque 20 af de beste Exemplarer."

Niebuhr havde tænkt sig før rejsebeskrivelsen at udgive to værker, nemlig en besvarelse af de til de rejsende stillede spørgsmål, uddraget af hans egne og Peter Forsskåls (1732-1763) efterladte papirer, og hans egne samlede astronomiske observationer (d.v.s. stedbestemmelser).

Han fandt imidlertid, at svarene på spørgsmålene var alt for ubetydelige til at udgives særskilt og lod dem derfor indgå i Beschreibung von Arabien.
Niebuhrs læremester i astronomi, professor Mayer i Göttingen var død og kunne ikke efterprøve hans beregninger, men i København befandt sig en kendt astronom, Maximilian Hell (17201792), som kongen havde indbudt til at observere venuspassagen 1769. Han var imidlertid modstander af Mayers metode til bestemmelse af den geografiske længde og afviste at kontrollere Niebuhrs beregninger.

Offentliggørelsen af hovedparten af de astronomiske observationer blev derfor udskudt indtil der kunne findes en astronom, der ville påtage sig dette arbejde.

Niebuhr var i disse år ven med Balthasar Münter (1735-93), sognepræst ved St. Petri tyske kirke i København.

Både Münters søn Friederich og hans datter Friederike Brun har omtalt dette venskab. Sidstnævnte skriver "Niebuhr lærte min far at kende, og snart blev han hans ven og daglige omgangsfælle. - - - Han arbejdede på udgivelsen af sit ypperlige værk, rådførte sig med min far om mange ting og medbragte de første aftryk af kobberpladerne og tegningerne."

I indledningen til Beschreibung von Arabien skriver Niebuhr "En lærd ven, som jeg ville nævne her, hvis ikke han havde forbudt mig det, har gennemgået mit manuskript og forbedret stilen mange steder."

$$
\text { Måske var denne lærde ven }
$$

Münter.

\section{Beschreibung von Arabien ud-}

kom i 1772 og blev modtaget forholdsvis lunkent.

Niebuhr regnede med en mere levende interesse uden for Tyskland og herpå var en fransk oversættelse beregnet. Description de l'Arabie oversat af Frédéric- 


\section{Carsten Niebuhr}

Carsten Niebuhr (1733-1815) var løjtnant i Ingeniørkorpset og blev udpeget som deltager i Den Arabiske Rejse (1761-67), en stort anlagt videnskabelig ekspedition, der desuden bestod af filologen F.C. von Haven, P. Forsskål, botaniker og naturforsker, lægen C.C. Kramer samt kobberstikkeren og tegneren G.W. Baurenfeind og oppasseren Berggren. I Yemen døde Haven og Forsskål, og på sejlturen mod Bombay døde Baurenfeind og Berggreen. Da Kramer efterfølgende døde i Bombay blev Carsten Niebuhr alene om at fuldføre ekspeditionen.

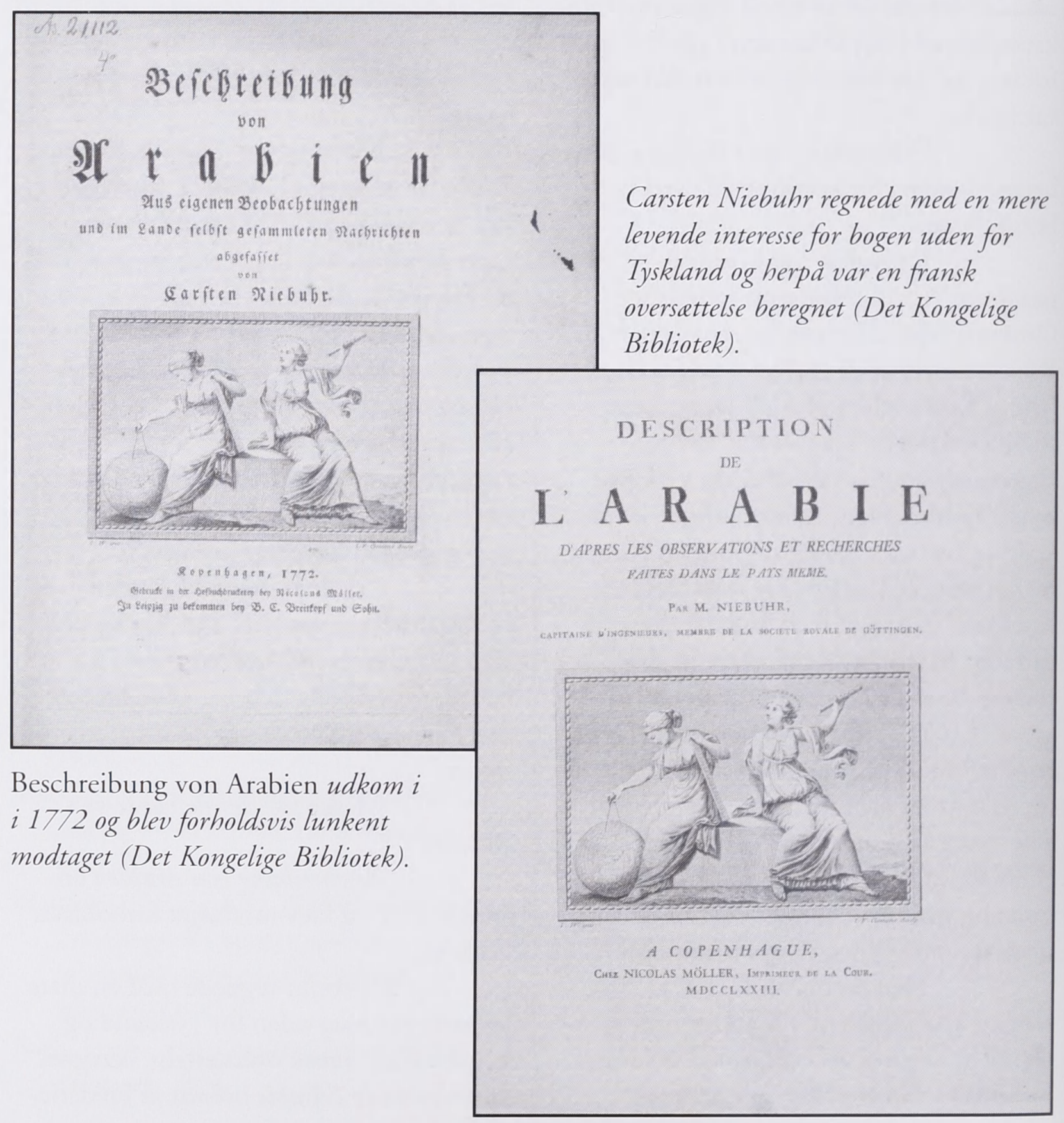




\section{Cariten פiebubr

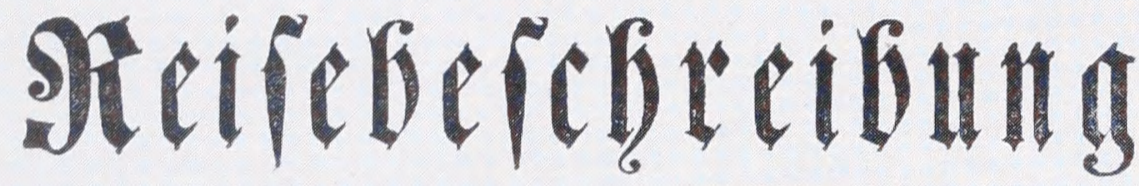 \\ $\operatorname{nach}$}

शrabien und andern umliegenden \&ántoent.

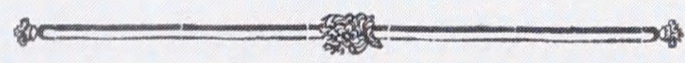

Eriter Ṡad.

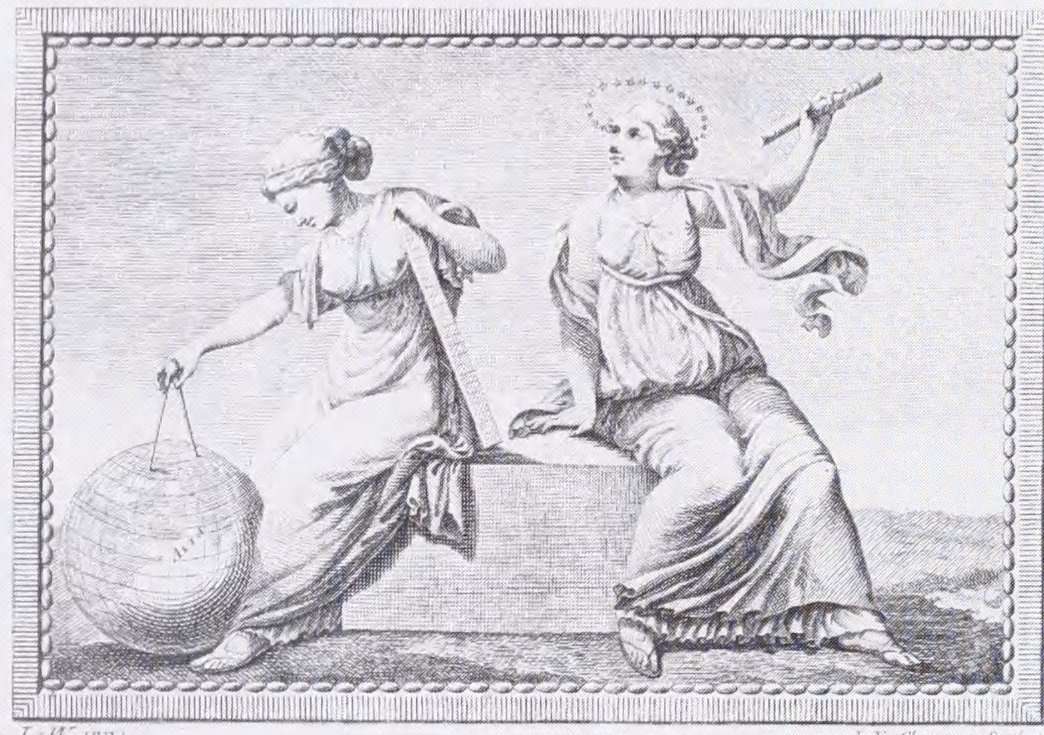

ก $0 \mathfrak{p} \in \mathfrak{n l} \mathfrak{a} \mathfrak{g} \in \mathbb{n}$,

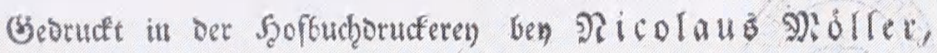

1774 .

I 1774 udkom forste bind af Reisebeschreibung nach Arabien und andern umliegenden Ländern. Andet bind udkom 1778 mens tredie og sidste del forst blev udgivet i 1837 - 59 àr senere (Det Kongelige Bibliotek). 
Moïse Mourier, præst ved den reformerte kirke i København, udkom i 1773. Men dels havde en hollandsk forlægger haft samme spekulation og udførte den på samme tid, dels var Mouriers oversættelse ifølge Carsten Niebuhrs søn, B.G.

Niebuhr, meget slet, ja nærmest ulæselig.

Carsten Niebuhr, som kun til

nød forstod fransk, kunne ikke bedømme oversættelsen og tabte mange penge ved dette foretagende.

I 1774 udkom første bind af

Reisebeschreibung nach Arabien und andern umliegenden Ländern.

Danmarks daværende udenrigsminister A.P. Bernstorffs (1735-97) ønske om publicering af Forsskåls manuskripter resulterede i en kongelig befaling til Niebuhr om at besørge udgivelsen af disse.

Manuskripterne kunne imidlertid ikke trykkes så uordnede som de var og Niebuhr kunne ikke påtage sig at redigere dem da han var ukyndig i botanik og zoologi og ikke særlig god til latin. Han ansatte en svensk lærd, som det siden hen ikke er lykkedes at identificere, til dette arbejde og betalte ham et meget betydeligt honorar. 1775 udkom først Descriptiones animalium og derefter Flora AgyptiacoArabica.

Da salget var utrolig ringe, forårsagede disse udgivelser det største tab blandt alle hans forlæggerforetagender.

I 1776 udgav han Icones rerum naturalium med Baurenfeinds tegninger af planter og dyr. Teksten er af daværende renteskriver Johan Zoega.

Andet bind af Reisebeschreibung nach Arabien und andern umliegenden Ländern udkom 1778.

Den sidste del af rejsen samt afhandlinger om det tyrkiske rige og om Islam, efterretninger om Etiopien og om Su- dan, endelig de samlede astronomiske iagttagelser skulle udgøre det tredje bind, hvilket han dengang troede at kunne lade følge snart efter. Det kom først 59 år senere i 1837.

B.G. Niebuhr udgav 1816 Carsten Niebuhrs Leben. Han skriver her at faderen Niebuhr forlod militæret og København i 1778 dels fordi han hørte, at hans militære overordnede havde i sinde at sende ham til Norge dels p.g.a. nogle misforståelser, som ikke bliver forklaret nærmere.

Friederich Münter skrev til forfatteren og takkede for "den finfølelse, hvormed De omtaler de misforståelser, som delvis bevægede Deres fader til at forlade København."

Misforståelserne forklares af Friederike Brun i hendes ungdomserindringer: Niebuhr havde giftet sig med en af Fru Münters veninder, som var en steddatter af den i 1774 afdøde Rohn, der havde været præst ved St. Petri kirke.

Nogen gjorde Niebuhr opmærksom på, at Rohns arvinger ikke havde modtaget en sum på 5-600 rigsdaler som følge af nådensåret (d.v.s. i det dengang lovbestemte tidsrum i hvilket en afgået præst, hans bo eller arvinger nyder andel i præsteembedets indtægter - herunder ret til at bebo embedsboligen - efter præstens afgang) af hans efterfølger, og Carsten Niebuhr mente på samtlige arvingers vegne at han burde afkræve Münter pengene, eftersom han beboede den gamles hus.

Münter svarede, at han ganske vist havde fået boligen efter Rohns død og Resewitz' afrejse; men han var Haubers efterfølger og skyldte derfor ikke Rohns arvinger noget.

Niebuhr ville sætte sin vilje 


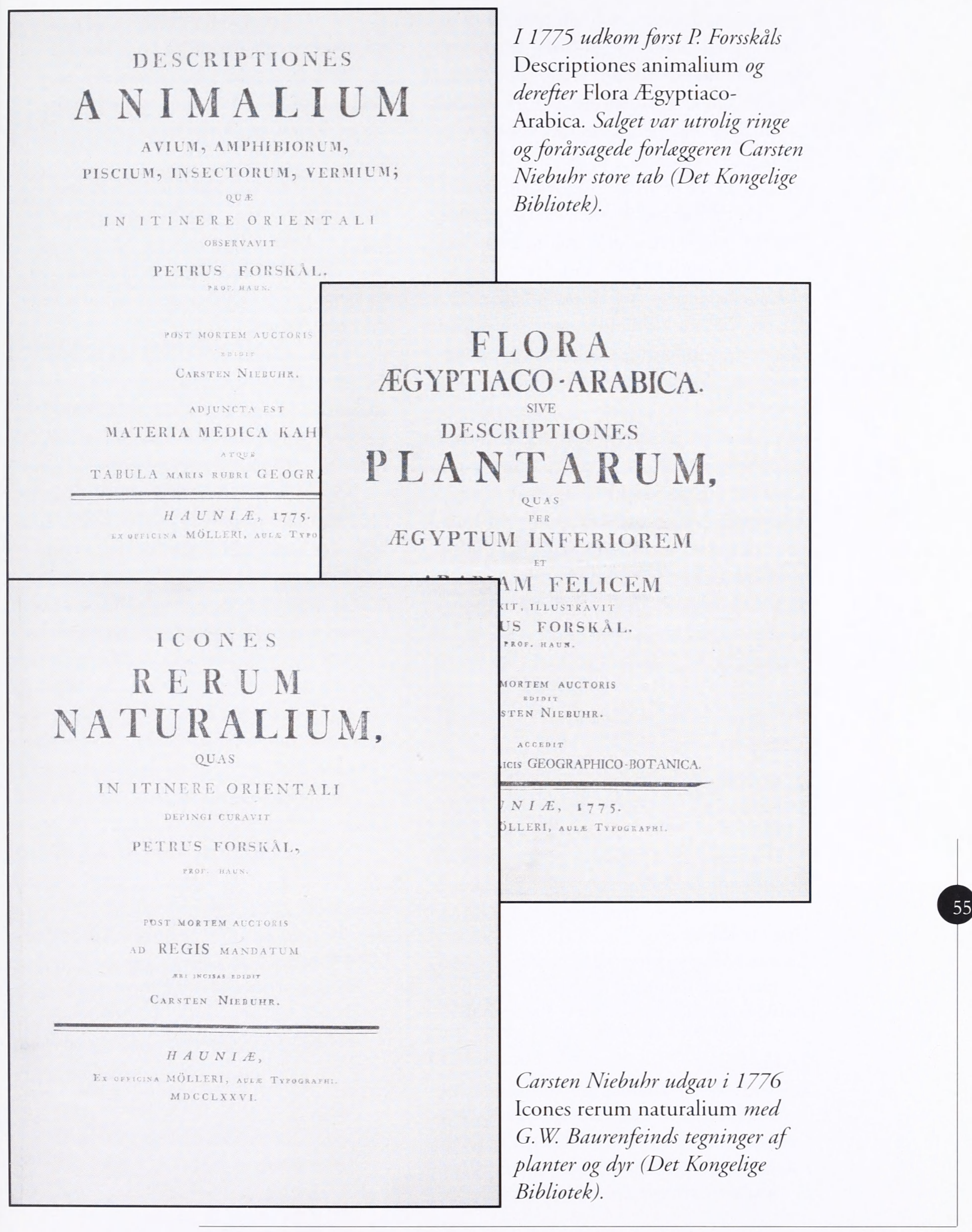


igennem og spurgte en lovkyndig til råds. Münter bad denne om at bilægge striden, således at han (Münter) ved at give efter forpligtedes til at udbetale beløbet, hvilket han med glæde ville, bare han beholdt Niebuhrs venskab.

Advokaten indvilligede i det fromme bedrag og alt ville være gået godt, hvis det ikke havde været for indblanding fra en falsk ven. Denne mand, som

Münter betroede sin hemmelighed, røbede den til Niebuhr ikke uden ondskabsfuld tilsætning om Münters stolthed og ønske om at tage sig højsindet ud. Nu ville Niebuhr have en proces, som han tabte sammen med omkostningerne. De to veninder bevarede deres trofasthed over for hinanden og gjorde alt for igen at forene de to mænd; men det var umuligt at bøje Niebuhrs sind. Han kunne aldrig komme over, at han havde haft uret. Kort efter flyttede Niebuhrs til Holsten. Såvidt Friederike Brun.
56

Utrykte kilder

Carsten Niebuhrs breve til Michaëlis (Fotokopier i Det Kongelige Bibliotek).

Partikulærkassens regnskaber (I Rigsarkivet).

Trykte kilder

Friederike Brun: Wahrheit aus Morgenträumen. 1824. Dansk oversættelse af Louis Bobé med titlen Ungdoms-Erindringer. 1917.

Ad. Langguth: Christian Hieronymus Esmarch und der Göttinger Dichterbund. 1903.
Louis Bobé skriver i en note til sin oversættelse af hendes bog: Ved Hofog Stadsrettens dom bestemtes det, at Rohns arvinger af dennes embedsefterfølger, Resewitz, skulle have udbetalt 600 rigsdaler.

En ven af familien Münter, C. H. Esmarch, skrev 1780 i sin dagbog: Årsagen til uvenskabet mellem Münter og Niebuhr var til dels også, at Niebuhr var en fjende af kristendommen og satte hinduismen højere.

Carsten Niebuhr søgte, som tidligere nævnt, om afsked fra militæret og ansættelse i et civilt embede i Holsten i 1778. Regeringen opfyldte hans ønsker og anviste ham landskriverembedet i Meldorf.

Venskabet mellem Niebuhr og Münter blev genoprettet 1790 under et af Münters besøg i Holsten, skriver Friederike Brun og Friederich Münter, men Niebuhr kom aldrig senere til København og som forlægger optrådte han ikke mere.

J.D. Michaëlis: Von Zubereitung des Forskalischen und von Havenschen Reisediarii zum Druck.. I: Orientalische und exegetische Bibliothek 5 (1773), s. 215 217.

Frederik Münter. Et mindeskrift. I-VII. 19251949.

B.G. Niebuhr: Carsten Niebuhr's Leben. I: Kieler Blätter 3 (1816), s. 1-86. 